\title{
Review on Thermocline Storage Effectiveness for Concentrating Solar Power Plant
}

\author{
Bagre Boubou1,2, Ibrahim Kalawole Muritala3, Boukar Makinta1, Daho Tizane'2, \\ Tubreoumya Guy Christian², Nebie Jacques², Dabilgou Téré2, Bere Antoine², \\ Adamou Rabani²
}

${ }^{1}$ West African Science Service Center on Climate Change and Adapted Land Use, Graduate Research Program on Energy and Climate Change, Université, Abdou Moumouni de Niamey, Niger

${ }^{2}$ Laboratoire de Physique et de Chimie de l'Environnement de l'Université Joseph KI-ZERBO, Ouagadougou, Burkina Faso ${ }^{3}$ Institute of Low Carbon Industrial Process of German Aerospace Center (DLR), Deutches Zentrum, Germany

Email: bagre.b@edu.wascal.org

How to cite this paper: Boubou, B., Muritala, I.K., Makinta, B., Tizane, D., Christian, T.G., Jacques, N., Téré, D., Antoine, B. and Rabani, A. (2021) Review on Thermocline Storage Effectiveness for Concentrating Solar Power Plant. Energy and Power Engineering, 13, 343-364.

https://doi.org/10.4236/epe.2021.1310024

Received: July 24, 2021

Accepted: October 19, 2021

Published: October 22, 2021

Copyright (C) 2021 by author(s) and Scientific Research Publishing Inc. This work is licensed under the Creative Commons Attribution International License (CC BY 4.0).

http://creativecommons.org/licenses/by/4.0/

\begin{abstract}
In this paper, a literature review on thermocline storage performance for Concentrating Solar Power (CSP) plant storage systems has been conducted. The efficiency of materials to store heat depends on the storage process like sensible heat storage, latent heat storage and thermochemical one and also on their properties. This study has been focused on sensible heat storage materials especially thermocline storage system (DMT) using eco-materials which has a high potentiality (35\%) to reduce CSP cost. There is a possibility to use natural rocks, industry waste and to develop also materials for a thermocline storage within a bed called packed bed using one tank. The thermal storage materials should have some optimum parameters (particle diameter less than 2 $\mathrm{cm}$ and good thermo-physical properties) to achieve better thermal storage performance (thermal cycle efficiency, extraction factor). However, the size and the shape of natural rocks are uncontrollable (big diameter) and can drive to thermocline degradation, catastrophic thermal ratcheting and poor thermal stratification due to the variability of the storage system porosity and the stress on the storage tank wall. Also a better thermal storage efficiency is achievable at low velocity and with good thermo-physical properties of the HTF. The ratio H/D, the height, the porosity, the shape and the position of the tank should be optimized to increase the storage efficiency.
\end{abstract}

\section{Keywords}

Thermocline Storage, Storage Effectiveness, Storage Materials, Optimum Parameters 


\section{Introduction}

The global demand for energy is growing and conventional resources like coal and petroleum are depleting, renewable resources is expected to play a crucial role in the future. One promising of these renewable resources technologies is concentrating solar power (CSP) plants [1]. However, CSP technology affordability is suffering from energy storage system for electricity dispatching during the night-time and cloud cover. This is explained by the important initial investment of $15 \%$ to $20 \%$ due to the two-tank storage system and the high price of heat transfer fluid (HTF) like mineral oil and synthetic oil, use also as storage medium since 1984 at SEGS plant [2]. Another challenge of mineral oil is the high risk of flammability, for example in 2009 the solar field of Andasol CSP plant in Spain took fire [3]. To face these challenges in 2004, an engineering study has shown the possibility of reduction of $10 \%$ of levelized electricity cost using molten salt in the medium storage [2]. Become the most effective thermal energy storage material, most CSP plant like Andasol, Ouarzazate have molten salt as storage medium material [4] [5]. The molten salt is also compromised because of its high melting temperature and the complex management of its thermal stability [3] [6] [7]. Apart from the high cost, low thermal stability of mineral oil and molten salt, these materials have a negative impact on the environment. Though, studies have shown that there is a possibility to have a broad reduction of CSP cost (33\% to 35\%) by cancelling one tank of the storage system and using eco-materials (natural rocks, industrial waste) as filler materials [4] [8]. But about $33 \%$ of molten salt withdrawn from the thermocline are below the nominal temperature of storing [4]. This work aims to assess the effectiveness of thermocline storage system. To achieve this objective, we will assess the different thermocline storage materials. Look in the literature the output of different thermoclines projects, their efficiencies and the different parameters that influence thermocline efficiency to see how to improve its performances for CSP plants. A thermocline tank is one that uses a single tank to store thermal energy. There is thermocline tank in experimentation at Solar One, University of Bayreuth, Ait Baba, JÜLICH etc. [9] [10] [11] [12]. In this tank a thermal gradient separates the hot zone from the cold one. The word thermocline is from oceanic language. It designates the thermal transition zone between the superficial waters and the deep waters. At the top and the bottom of thermocline zone, temperatures are quasi-uniform, while the difference of temperature is important in the width of thermocline [3]. There is two type of thermocline system. When the tank use only fluid like molten salt, it is called a single-medium thermocline (SMT). To reduce the amount of molten salt required, a granulated material is added to have a dual-media thermocline (DMT) with economical and technical advantages over SMT tanks [13] as presented in Figure 1.

The single-medium thermocline is active storage system while the DMT can be both active and passive also called regenerators [12] [14]. When the thermal capacity of the heat transfer fluid (HTF) is significant and contribute to the 


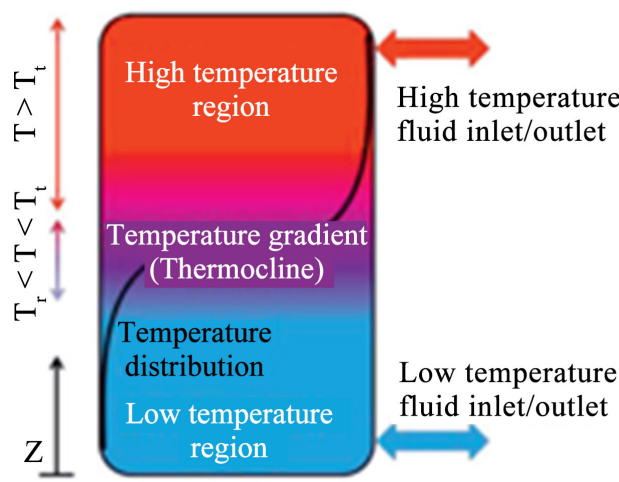

(a)

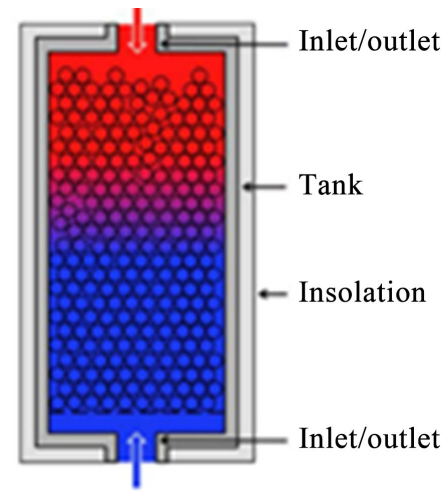

(b)

Figure 1. (a) Single-medium thermocline (SMT); (b) Dual-medium thermocline (DMT) [3] [4].

whole storage capacity, the DMT is a dual-medium system (active passive) [14] [15]. When gas or air is used as HTF the storage is passive.

In the following section the effectiveness on the different type of thermocline storage system are presented. With more focused on DMT system the effects of some key design parameters such as the inlet temperature and fluid flow (velocity), fluid properties, filler materials diameter and their thermal properties, tank porosity, and the tank aspect ratio, shape and position on the thermal performance of the thermocline TES are presented based on literature analysis.

\section{Thermocline Systems and Their Effectiveness}

\subsection{Single-Medium Thermocline Systems and Their Effectiveness}

The performance of a SMT is determine by the thermal stability, thermal capacity the maximal temperature of the HTF the melting point, compatibility of the storage material with the tank wall avoiding any corrosion [7] [16]. In case of indirect active storage, the HTF like oil should have a low vapour pressure, high flammability temperature, low cost and low impact on environment. One of the first CSP pilot plants has used one tank as thermocline storage system is Solar One since 1983. The strategy of this storage system was to supply auxiliary steam needs of the pilot power plant and experimentation for the thermal storage system. Oil has been used in the storage medium and heat transfer fluid through heat-exchanger. But in august 1986, this routine operation was interrupted because of the produced fire at the top of the tank due to over pressurization and the rupture of the thermal storage tank caused by significant quantities of water in the heat transfer fluid (oil) [17]. So most of STM systems are commonly used for industrial refrigeration systems and domestic solar thermal devices. To maintain under static and dynamic conditions a thermocline Abdouly et al. studying in 1982 the static and dynamic properties of a water thermocline carried out a possibility degradation of the thermocline due to heat mechanism losses through the insulation. Also, the tank should have an optimal size (length $>10 \mathrm{ft}$, diameter $>1.5 \mathrm{ft}$ and insulation resistance $>20 \mathrm{hr} \cdot \mathrm{ft}^{2} \mathrm{~F} / \mathrm{B} . \mathrm{t} . \mathrm{u}$ ) [18]. Water has an excel- 
lent specific heat $(4.19 \mathrm{~kJ} / \mathrm{kg} \mathrm{K})$ but the system need to be pressurized at above $100^{\circ} \mathrm{C}$, which adds tremendously to cost, increase accident risk [19]. Exploration trough numerical simulation has shown a higher thermal performance of molten salt SMT than the DMT one because there is absence of thermal ratcheting. But molten salt SMT tank is more sensitive to flow disturbances and have less cost-effectiveness [13]. The main equations governing take into account the motion of the fluid inside the tank that obeys the mass and momentum conservation principles as expressed in the following laminar flow equations. Darcy's and Forchheimer's terms must be included to account for viscous and momentum dissipation in the porous bed:

$$
\begin{gathered}
\frac{\partial \rho}{\partial t}+\nabla \cdot(\rho u)=0 \\
\frac{\partial(\rho u)}{\partial t}+\nabla \cdot(u u)=-\Delta p+\nabla \tau+\rho g
\end{gathered}
$$

One equation is required for a SMT tank. The effective thermal conductivity is equal to the thermal conductivity

$$
\frac{\partial\left(\rho c_{p} T\right)}{\partial t}+\nabla \cdot\left(\rho u c_{p} T\right)=\nabla(\kappa \nabla T)+\mu \vartheta
$$

where $\rho$ is the density, $c_{p}$ the specific heat, $T$ fluid temperature, $K$ thermal conductivity, $\mu$ the viscosity of the fluid and $\varnothing$ viscous dissipation function; $\nabla$ defines the dimension of the model (1D, 2D or 3D).

Based on these models, researches have carried out the influence of the ratio height over diameter (H/D) and tank position on thermal stratification. In 2017 Burak et al. have found optimal values of $0.5^{\circ}$ and $45^{\circ}$ respectively for the ratio and tank position angle for water thermocline storage tank with $93 \%$ of stratification efficiency [20]. Bent inlet geometry design is required to have a good stratification for the Reynolds number between 7500 and 20,500 and for HTF velocity between $0.11-0.16 \mathrm{~m} / \mathrm{s}$ [21].

\subsection{Dual-Medium Thermocline System and Its Effectiveness}

Most of CSP pilot and laboratory scale projects for thermocline storage studied are dual-medium thermocline [10] [11] [12] [17] [22] [23] [24]. DMT tanks are favored because they have economical and technical advantage. The filler material reduces the quantity of the liquid material (oil, molten salt) which is often the most expensive. But many parameters need to be considered to have a good thermal stratification therefore good extraction of the thermocline during charging and discharging time. Solar One CSP pilot plant is one of the first plant where

DMT system has been experimented since 1982. The storage system was sized to generate $7 \mathrm{MWe}$ during four hours. The thermal storage system employs dual liquid (Caloria HT-43) and solid (quartzite and sand) storage media in a thermal storage tank with $13.8 \mathrm{~m}$ of height, $18.3 \mathrm{~m}$ of diameter and $0.304 \mathrm{~m}$ of external insulation. The HTF (Caloria HT-43) was heat from $218^{\circ} \mathrm{C}$ to $304^{\circ} \mathrm{C}$ and was 
heated indirectly through heat exchanger by the steam from the receiver. Thermal-to-electric efficiency was $25 \%$ from thermal storage steam instead of $35 \%$ because of the limitation to use oil more than $304^{\circ} \mathrm{C}$ (ovoid vaporization) and the indirect storage method [25]. In 2012 the thermo mechanical performance simulation (infinite rigidity approach for the solid filler) of the Solar One thermocline storage tank by Scott linked the stresses along the tank wall to some finite amount of solid filler volume change due to thermal expansion and mechanical interactions; because the measured horizontal stress achieved $190 \mathrm{MPa}$ again $177 \mathrm{MPa}$ from numerical investigation (6.8\% of deviation) [9]. Moreover the thermal performance of the molten salt packed-bed investigated in 2013 [26] carried out the impact of solid particles size on thermocline performance. The efficiency is the highest for the particles diameter smaller than $1.9 \mathrm{~cm}$. The discharge time increase with thermal capacity (energy density) trough different solid particle material. And also the particle should have an optimal thermal conductivity [27] to easier release heat during discharge time [26]. Solid particle like cast iron and ceramics have long discharge but may have issue of availability and cost effectiveness, while rock like quartzite rock have a good discharge efficiency and available with effective cost. That explains the use of quartzite/sand in the first thermocline storage tank (solar one) and why rocks are being experimented as thermal energy storage materials. But the uncontrolled shape and size impact the thermocline efficiency (big size, not well shape) [3]. In addition, the storage tank impacts the storage efficiency through insulation, its size and wall. The heat losses have to be taken into account for small tanks to correctly predict outlet temperature, but can be negligible for large-scale tank, also the tank wall may exert non-negligible effect on temperature profile inside the tank [28]. The thermal storage efficiency increase with the ratio height over diameter(H/D) and should have a minimum value of 2.3948 [29] because resulting in higher velocities of the HTF. And drive to a better heat transfer with the solid particles [27]. The optimal height of tank could be $30 \mathrm{~m}$ according to Angelini et al., [4]. Also, different HTFs may influence the thermal performance of the thermocline through the porosity of the tank. When the porosity increase from 0.1 to 0.7 the effectiveness of the storage tank decrease and could be more suitable with therminol oil than molten salt like solar salt [30].

\subsubsection{Governing Equation}

To evaluate the effect of tank properties (size, shape, porosity, position), filler material properties and HTF properties on the performance or the behaviors of packed-bed thermocline system; most of the models developed in the literature are based on Schuman equations developed since 1929 [31]. This one-dimension model was used for porous medium modelling and combined two energy equations. One for the fluid and one for the solid particles.

$$
\varepsilon \rho_{f} c_{p f}\left(\frac{\partial T_{f}}{\partial t}+u \frac{\partial T_{f}}{\partial z}\right)=h \cdot a_{s} \cdot\left(T_{s}-T_{f}\right)
$$




$$
(1-\varepsilon) \rho_{s} c_{p s} \cdot \frac{\partial T_{s}}{\partial t}=h \cdot a_{s} \cdot\left(T_{f}-T_{s}\right)
$$

where $a_{s}$ is representing solid surface per volume unit of the bed in $\mathrm{m}^{2} \cdot \mathrm{m}^{-3}, T_{s}$ solid temperature, $T_{f}$ and fluid temperature in ${ }^{\circ} \mathrm{C}, h$ convective heat capacity coefficient in $\mathrm{W} \cdot \mathrm{m}^{2} \cdot \mathrm{K}^{-1}, u$ the velocity of the fluid in $\mathrm{m} / \mathrm{s}, \varepsilon$ porosity of the porous medium, $\rho_{f}$ the density of the fluid in $\mathrm{kg} \cdot \mathrm{m}^{-3}, c_{p f}$ the specific heat capacity of the fluid in $\mathrm{J} \cdot \mathrm{kg}^{-1} \cdot \mathrm{K}^{-1}$.

$\rho_{s}$ the density of the soild in $\mathrm{kg} \cdot \mathrm{m}^{-3}, c_{p s}$ the specific heat capacity of the solid in $\mathrm{J} \cdot \mathrm{kg}^{-1} \cdot \mathrm{K}^{-1}$.

For better understanding thermocline behaviors, the thermal losses, the effective conductivities of the fluid and solid, and tank thermal capacity have been added to Schuman model [24] [32]. And energy balance for the tank wall has been taken into account. Through the years to better analyze temperature distribution based on continuous solid phase assumption and fluid flow the model two dimension [33] and three dimension [9] [23] [34] [35] respectively have been developed. The general description of these models with three equations is presented as follow:

- Energy equation for the fluid

$$
\varepsilon \rho_{f} c_{p f}\left(\frac{\partial T_{f}}{\partial t}+\nabla u \frac{\partial T_{f}}{\partial z}\right)=\nabla\left(\kappa_{f, \text { eff }} \nabla T_{f}\right)+h_{v}\left(T_{s}-T_{f}\right)+U_{u \cdot f w}\left(T_{W}-T_{f}\right)
$$

- Energy equation for the solid particles

$$
(1-\varepsilon) \rho_{s} c_{p s} \cdot \frac{\partial T_{s}}{\partial t}=\nabla\left(\kappa_{s, e f f} \nabla T_{s}\right)+h_{v s}\left(T_{f}-T_{s}\right)+U_{u . s w}\left(T_{w}-T_{s}\right)
$$

- Energy equation for the tank wall.

$$
\rho_{w} c_{p w} \cdot \frac{\partial T_{w}}{\partial t}=\nabla\left(\kappa_{w, \text { eff }} \nabla T_{w}\right)+U_{v . f w}\left(T_{f}-T_{w}\right)+U_{w . s w}\left(T_{s}-T_{w}\right)+h_{v, e x t}\left(T_{W}-T_{e x t}\right)
$$

where $h_{V}$ convective heat transfer coefficient per unit bed volume in $\mathrm{W} \cdot \mathrm{m}^{-3} \cdot \mathrm{K}^{-1}$ $U_{u, f w}$ overall heat transfer coefficient between the tank wall and the fluid, $T_{w}$ the tank wall temperature, $U_{u, s w}$ overall heat transfer coefficient between the tank wall and the solid, $h_{v, \text { ext }}$ convective heat transfer coefficient per unit bed volume in $\mathrm{W} \cdot \mathrm{m}^{-3} \cdot \mathrm{K}^{-1}$ with ambient air.

A part from energy equations, continuity equation and momentum equation should be added [26]. According to the model dimension and the size of the tank several numerical methods like finite volume, finite element and different finite have been used to resolve these energy balance equations and study the performance of a thermocline storage system during thermal cycles. The important of numerical model is to have data from an ideal system and use it for experimental data validation. The three equation models provide an effective thermal performance study of a storage system than one equation [24]. Two equations model can effectively study thermocline behaviors [36] like three equations model by reducing $18 \%$ of computation time [32]. 


\subsubsection{Thermal Stratification}

Stratification in the storage tank results from buoyancy effects cause by density differences in the storage. The hotter fluid rises to the top and the colder fluid falls to the bottom [37]. This thermal stratification is among the key factors that can sensibly affect the performance of the TES system: the thinner of the thermocline, the thermodynamic quality of the energy stored. The thermal stratification efficiency into packed-bed can be compute as follow:

$$
\eta_{\text {MIX }}=\frac{\eta_{s t r}-\eta_{\text {exp }}}{\eta_{s t r}-\eta_{\text {mix }}}
$$

where $M_{\text {exp }}$ is the moment of the energy real TES, $M_{s t r}$ the moment of the ideally stratified TES and $M_{m i x}$ fully mixed TES.

Into a packed bed as thermocline storage system using gravel as filler material and air as HTF, the thermal stratification efficiency enhances with starting-up of thermal cycles. Based on moment of energy and one equation model for energy balance resolved with finite volume approach and 3D CFD simulations software, Simone et al. [38] have shown a stable thermal stratification after 30 cycles with 93\% as efficiency as showed in Figure 2 and Figure 3. This shown the important of pre-charging the TES system before the first cycles to reduce the long time required to achieve a stable thermal stratification [39]. Similar results were achieved by Ortega et al. using air as HTF and rocks as filler materials [39].

\subsubsection{Thermal Cycle Effectiveness}

From Figure 3 we can assume that the stratification efficiency could depend on the charge and discharge efficiency which is influenced by porosity of the tank, particles size, and storage capacity [27]. Moreover thermocline thickness defined as the covering length of the thermocline region depend on charging and discharging cycle and can be defined according to Chang et al. [40] by

$$
\begin{gathered}
d X=\min \left\{H\left(T_{\text {out }}, T_{\text {crit }, h}\right)\right\}-H\left(T_{\text {crit }, C}\right) \text { in dicharging cycle } \\
d X=H\left(T_{\text {crit }, C}\right)-\max \left\{H\left(T_{\text {out }}, T_{\text {crit }, h}\right)\right\} \text { in charging cycle }
\end{gathered}
$$

where $T_{\text {crit }, h}=T_{h}-5$ and $T_{\text {crit, } c}=T_{c}+5$ Represent the critical low and hot temperature for evaluating the thermocline thickness respectively. From there we can realize that a thin thermocline can be achieved with an effective thermal stratification and thermal cycle. A thin thermocline thickness can conduct to a good cycle efficiency defined as follow:

$$
\eta=\frac{Q_{\text {dish }}}{Q_{c h g}}=\frac{\int_{0}^{t_{\text {dish }}} \dot{m} c_{p, f}\left(T_{\text {out }}-T_{\text {min }}\right) \mathrm{d} t}{\int_{0}^{t_{\text {dish }}} \dot{m} c_{p, f}\left(T_{\max }-T_{\min }\right) \mathrm{d} t}
$$

where $\eta$ is the effective discharge efficiency, $t_{\text {dis }}=t_{\text {dis, ref }}$ is the time at which the HTF temperature drops to a threshold value. The threshold value is usually determined by the application of the interest and is arbitrary chosen like $T_{h}-5$, $T_{h}-20$ etc.

An effective thermal storage depends on the discharge efficiency and the discharge time. 


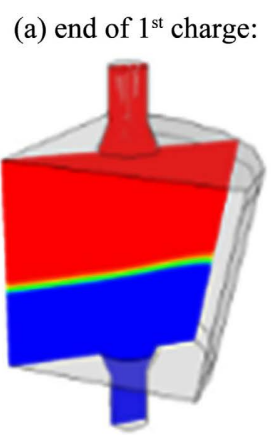

(d) end of $15^{\text {th }}$ charge:

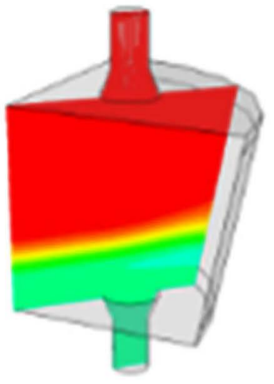

(b) end of $5^{\text {th }}$ charge

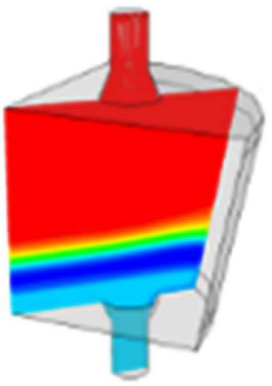

(e) end of $20^{\text {th }}$ charge

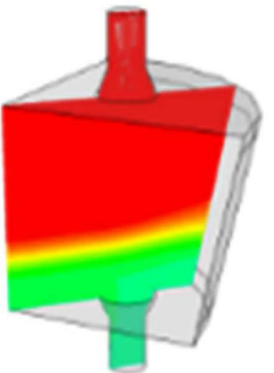

(b) end of $10^{\text {th }}$ charge

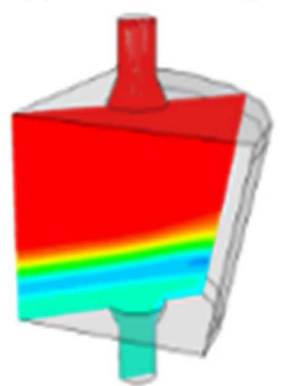

(f) end of $30^{\text {th }}$ charge

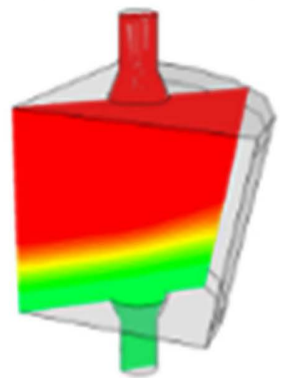

Figure 2. Thermal stratification enhancement with thermal cycles (end of each charge) [38].

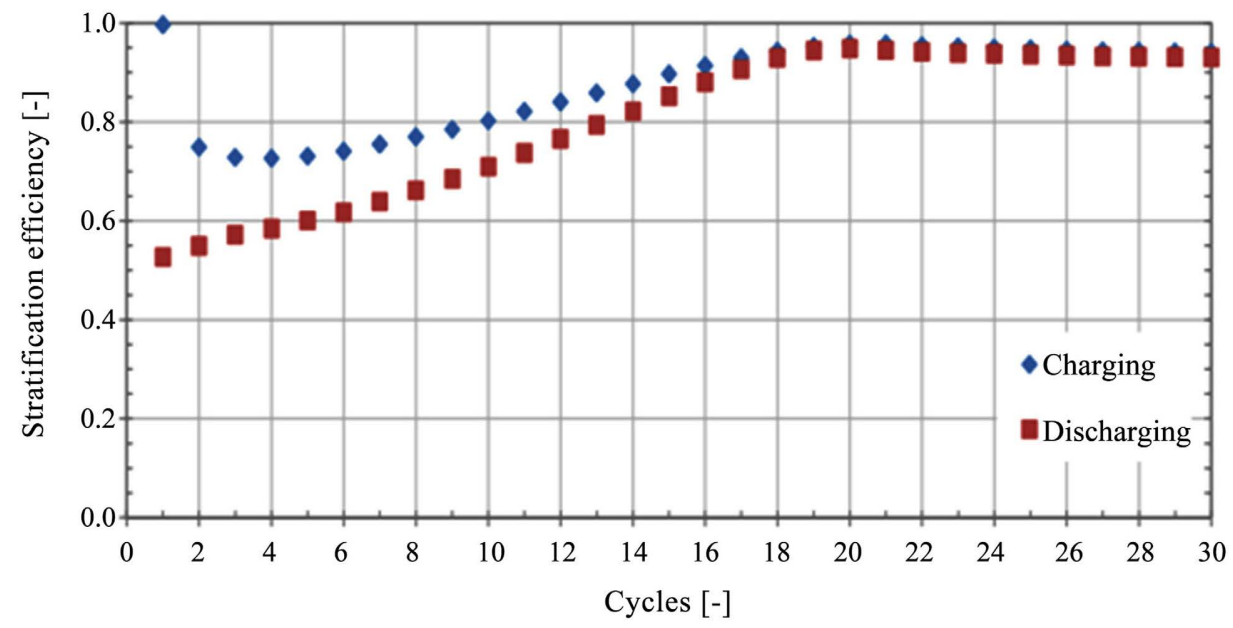

Figure 3. Average transient stratification efficiency for consecutive charge/discharge cycles [38].

\section{Parameters Affecting Thermocline Storage Performance}

\subsection{Particles Effect on Discharge Effectiveness}

Based on transient two-dimensional dispersion-concentric (D-C) model for heat transfer and fluid dynamics in a packed-bed molten salt thermocline thermal storage system $\mathrm{xu}$ et al. [26] have shown the possibility reduction discharge efficiency [26] with large particles confirmed by numerous other authors [26] [27] [41] as showed in Figure 4. 


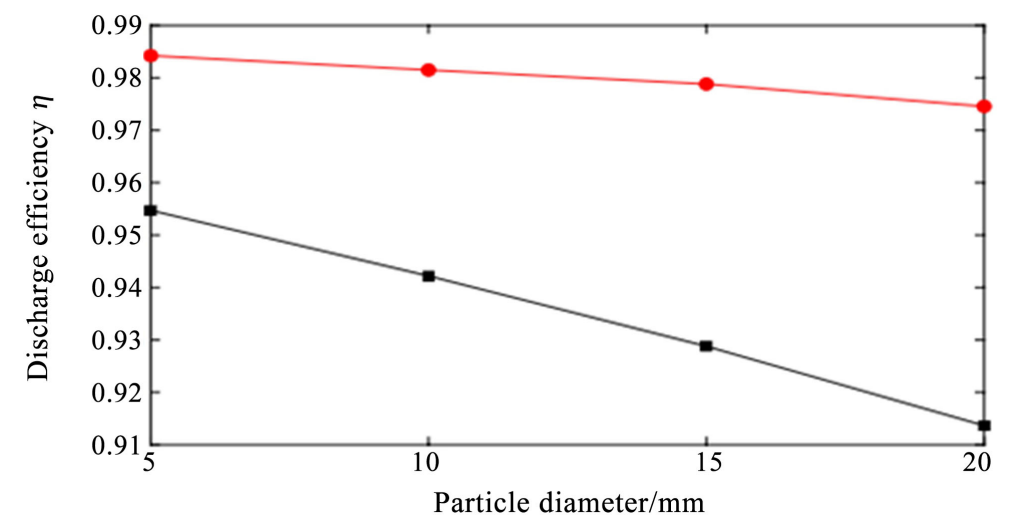

Figure 4. Effect of particle size on discharge efficiency [27].

To have a thin thermocline with an effective discharge efficiency and good discharge time, small particle diameter is required (less than $2 \mathrm{~cm}$ ) to avoid bad thermal distribution in the particle and provide a good heat transfer process between the fluid and the particle, but when the particle diameter is smaller enough, the influence of particle diameter on thermal performance becomes negligible [26]. Figure 5 presents the effect of particle diameter on thermocline efficiency.

A part from that, the thermal performance of a thermocline is influencing by the properties of the particles. The main properties governing the thermal performance of a filler material are the thermal conductivity, the density and volumetric heat capacity. Calcite and quartz are the main component governing these thermal and mechanical properties for natural rocks [42]. The thermal conductivity of the filler material influences the thermal distribution inside the tank. Greater thermal diffusion (increasing thermal lost) in DMT system may be explain by high thermal conductivity of the solid particle driving to bad thermal distribution and low thermal cycle efficiency [13]. This hypothesis can explain better the different results achieved by Keilany et all in 2018 using cofalit rock and aluminium sphere as filler materials than based on particles shape; the Cofalit with the lowest thermal conductivity (1.4 to $2.1 \mathrm{~W} \cdot \mathrm{m}^{-1} \cdot \mathrm{K}^{-1}$ for the Cofalit rock and 18 to $33 \mathrm{~W} \cdot \mathrm{m}^{-1} \cdot \mathrm{K}^{-1}$ for aluminium spheres) has shown the better thermal cycle efficiency ( $79 \%$ vs. $71 \%$ for discharge efficiency) and the thinner thermocline ( $26 \%$ vs. $33 \%)$ than aluminium sphere [43]. The thermal conductivity has to be optimum to ovoid heat increasing between adjacent particles when it is too high and heat discharge rate reduction when it is too low [26]. The different type of filler materials properties useful for DMT storage tank are noted in Table 1.

A good filler material of TES system must have thermo physical properties following aspects according to the given requirements of the application fields [50].

Density: High density improves energy storage density which reduces the tank volume of the TES system, as consequence reduction of land us. A minimum value of $2 \mathrm{M} \mathrm{J} \cdot \mathrm{m}^{-3} \cdot \mathrm{K}^{-1}$ is required [51]; specific heat: sensible heat storage materials should have high specific heat. High specific heat improves energy 


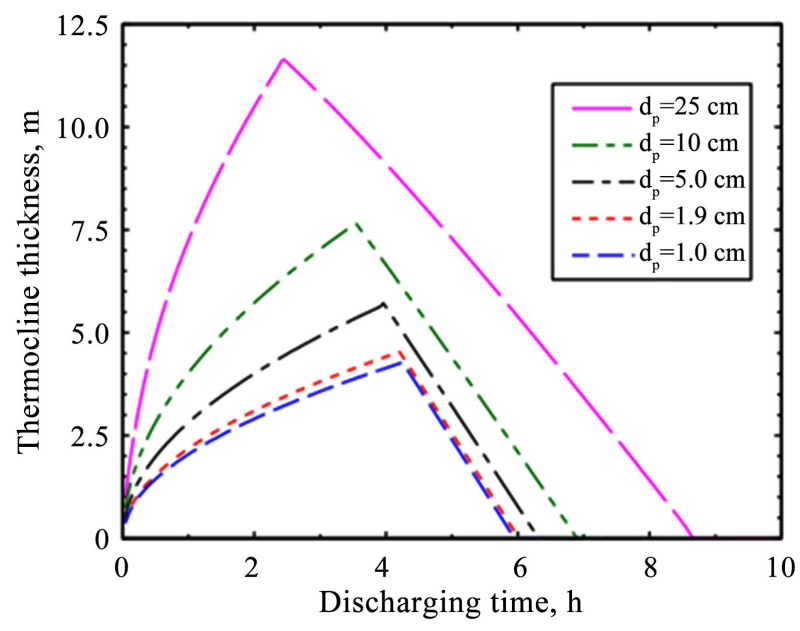

Figure 5. Variation of thermocline thickness with discharge time for quartzite rock particle diameters [26].

Table 1. Thermal properties and discharge efficiency of some storage materials.

\begin{tabular}{|c|c|c|c|c|c|c|}
\hline $\begin{array}{c}\text { Material } \\
\text { properties }\end{array}$ & $\begin{array}{c}\lambda \\
\mathrm{W} \cdot \mathrm{m}^{-1} \cdot \mathrm{K}^{-1}\end{array}$ & $\begin{array}{c}\rho \\
\left(\mathrm{kg} \cdot \mathrm{m}^{-3}\right)\end{array}$ & $\begin{array}{c}c_{p} \\
\mathrm{~J} \cdot \mathrm{kg}^{-1} \cdot \mathrm{K}^{-1}\end{array}$ & $\begin{array}{c}\rho c_{p} \\
\mathrm{~kJ} \cdot \mathrm{m}^{-1} \cdot \mathrm{K}^{-1}\end{array}$ & $\begin{array}{l}\eta_{d c h g} \\
(\%)\end{array}$ & $\begin{array}{l}T_{\max } \\
\left({ }^{\circ} \mathrm{C}\right)\end{array}$ \\
\hline \multicolumn{7}{|l|}{ 1. Rocks } \\
\hline River pebble [44] & & 2713.6 & & & & \\
\hline Pea pebble $[44]$ & 1.2 & 2506.3 & & & & \\
\hline Sand and quartzite [45] & 5.5 & 2600 & $973\left(200^{\circ} \mathrm{C}\right)$ & l & l & \\
\hline quartzite [26] & 5.69 & 2500 & 830 & 2075 & 90.43 & 650 \\
\hline Dune sand [35] [46] [47] & 1 & $2600-2660$ & 926 & I & l & 600 \\
\hline River sand & $/ /$ & $/ /$ & $/ /$ & // & $/ /$ & $/ /$ \\
\hline Quartzitic sandstone [42] & 5 & 2733 & $65225^{\circ} \mathrm{C}$ & $1783\left(25^{\circ} \mathrm{C}\right)$ & & 650 \\
\hline Rhyolite [42] & 2.3 & 2601 & 785 at $25^{\circ} \mathrm{C}$ & $2045\left(25^{\circ} \mathrm{C}\right)$ & l & 650 \\
\hline Silicate sand & // & $/ /$ & $/ /$ & // & $/ /$ & 600 \\
\hline \multicolumn{7}{|l|}{ 2. Developed materials } \\
\hline HighTemp concrete [26] & 1 & 2750 & 780 & 2519 & 91.69 & $\geq 370$ \\
\hline From ash and clay & $0.75-0.96$ & $1720-2140$ (R.D) & & $1700-1995$ & l & 1000 \\
\hline \multicolumn{7}{|l|}{ From laterite } \\
\hline Aluminium ceramic [26] & 30 & 3750 & 916 & 295 & 90.03 & $\geq 370$ \\
\hline S.C ceramic [26] & 120 & 3210 & 750 & 2407.5 & 90.70 & \\
\hline Den stone ceramic pebbles [33] & & & 700 & 1300 & & 900 \\
\hline Laterite ceramic [48] & $1.1-2.5$ & & 700 & 1300 & & 900 \\
\hline \multicolumn{7}{|l|}{ Industrial waste } \\
\hline Cast iron [26] & 29.3 & 7900 & 837 & 6612.3 & 89.7 & $\geq 370$ \\
\hline ACW ceramic [49] & $2.1-2.4$ & 3120 & $800-1034$ & $2496-3226$ & l & 1200 \\
\hline
\end{tabular}


storage density of the system.; thermal conductivity: high thermal conductivity increases the thermal charging and discharging rate which is desired. But a maximum value of $25 \mathrm{~W} \cdot \mathrm{m}^{-1} \cdot \mathrm{K}^{-1}$ is required to ovoid thermocline degradation. However, a recent work has showed the low effect of effective thermal conductivity on DMT storage performance [52]; thermal stability: the filler materials should not decompose at high temperatures. This gives wider operating temperature range and higher energy storage capacity for the material. Material properties should be stable even after extended thermal cycles of heating and cooling; chemical stability: high chemical stability of filler storage materials increases life of energy storage plant making them compatible with the HTF and the storage tank wall; particle size: smaller particles enhance thermal stratification, reduce the thickness of the thermocline, improve discharge efficiency thereby the storage efficiency. An optimal value of the particle size could range from $1 \mathrm{~cm}$ to $2 \mathrm{~cm}$ but should be less than $3 \mathrm{~cm}$ [26] [27] [53] depending on the storage material properties and type to reduce heat losses.

\subsection{Heat Transfer Fluid Effect on Thermocline Storage Effectiveness}

Heat transfer fluid must be compatible with the containment materials, storage media and be able to operate in the required temperature range. The HTF defines the maximal temperature to store in the packed bed and the range temperature of the power block (thermodynamic cycle). To have a large temperature range the HTF must be stable at high temperature. The main HTFs are mineral oil, air, molten salt and non-conventional HTFs like vegetal oils and liquid metal. A HTF impacts the thermal energy storage performance through:

Velocity: Several studies have shown the impact of the fluid velocity or inlet Reynolds number on thermal performance. Using molten salt as HTF, Xu et al. [54] have pointed out the increase of effective discharging time and discharging efficiency at low velocity of the fluid, and shown the possibility to achieve $9.1 \mathrm{~h}$ as discharging time at $3.0085 \times 10^{-4} \mathrm{~m} \cdot \mathrm{s}^{-1}$ of fluid speed with a discharge efficiency of $89.76 \%$ and $0.91 \mathrm{~h}$ as discharge time at $6.017 \times 10^{-3} \mathrm{~m} \cdot \mathrm{s}^{-1}$. But the influence of the velocity is negligible on thermocline development (Figure 6). The similar results have been achieved by Esence et al. [36] using monomodal approach and therminol ${ }^{\mathbb{R}} 66$ oil as HTF showing also the influence of fluid velocity on thermal stratification. At high velocity the heat flux exchange between the fluid and solid filler becomes lower than the flux conveyed by the fluid, which spreads the thermocline degrading thermal stratification. This degradation may be due to increase of the mixing coefficient [55]. However a possible reduction of heat losses and thermal diffusion can be possible at high fluid velocity, but driving to utilization rate reduction [36] observed experimentally by [34] [56].

HTF Inlet Temperature Effect: The inlet temperature or difference between inlet temperature and outlet temperature influences less the thermocline thickness and the discharge efficiency and discharge time [54]. However when the hot 


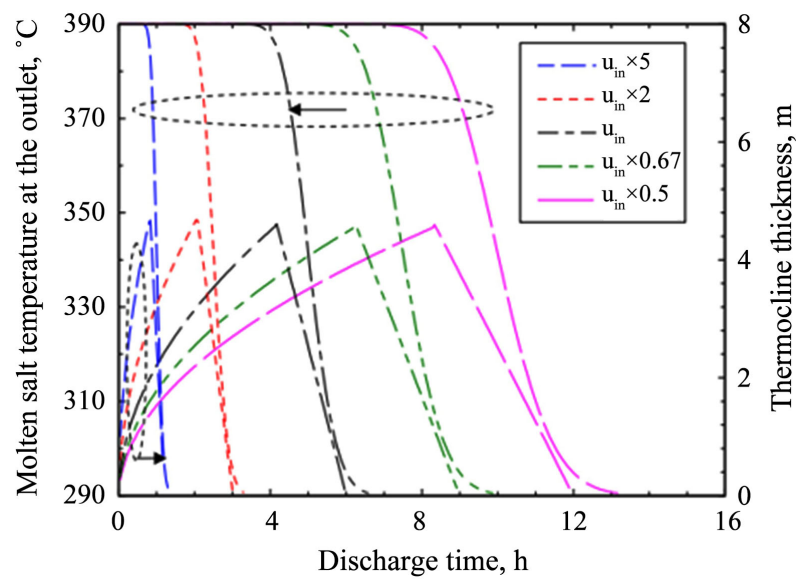

Figure 6. Variations in the fluid (molten salt) temperature at the outlet and the thermocline thickness with the discharging time using different fluid inlet velocities [54].

temperature (maximal temperature) of the storage system is too high it can reduce the charge and discharge time, making the storage less effective due to increase of thermal losses at high temperature [57]. In addition when the filler material is encapsulated PCM material, the inlet temperature during charging and discharging affects temperature distribution [58].

Influence of HTF Properties on Thermal Performance: The main properties of HTF influencing the performance of thermal energy storage are specific heat, density, kinetic viscosity and thermal conductivity. As these properties differ from one fluid to another, the thickness of the thermocline, the thermal cycle efficiency (charge/discharge) and the stability of tank storage capacity may be also different as shown in Figure 7.

The volumetric heat capacity $\left(\rho \cdot c_{p}\right)$ enables to assess the heat storage density of materials, while the thermal effusivity $\mathrm{E}$ enables to assess their ability to exchange heat. Liquid HTFs like molten salt and oils have good heat capacity and thermal conductivity compared to gasses. This enables liquid/solid systems to operate at low HTF velocity while keeping a good heat transfer coefficient (HTC), which improves thermal stratification [59]. A comparison study between a synthetic oil and rapeseed oil of thermocline performance base on the same sizing condition gave a better thermal performance for the synthetic oil showing thus the depending of thermal storage efficiency on thermal and thermo-physical properties, but rapeseed oil has given a better cost effectiveness [60]. Similar results have been found numerically by Cascetta et al. using molten salt, oil and air as HTFs, with a possibility to improve within a large temperature range the performance of the system working with air [61]. The influence of fluid properties like viscosity and thermal conductivity is responsible for maintaining thermocline thickness within the tank. Higher is the viscosity, faster the thermocline moves and may reduce the discharge time thereby the operation time [30]. Moreover, a HTF with very low (limiting the heat transfer between HTF and solid particle) and very high (increasing thermal diffusion) thermal 


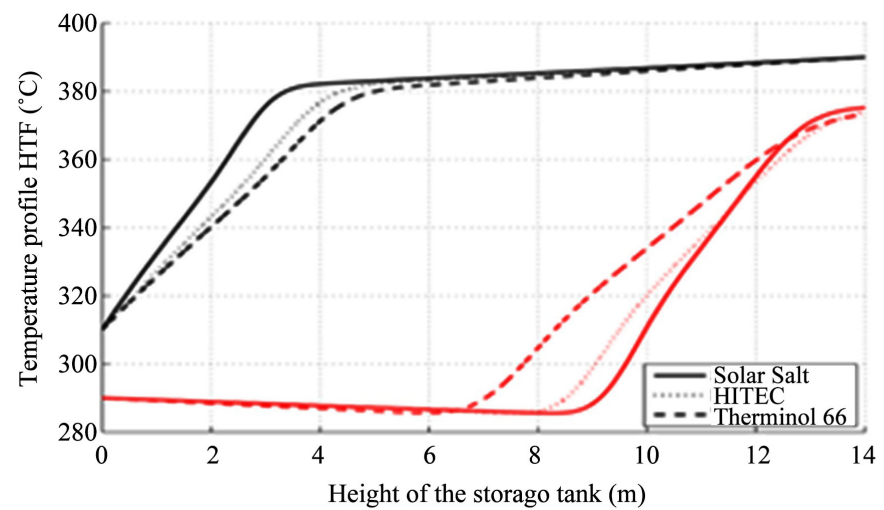

(a)

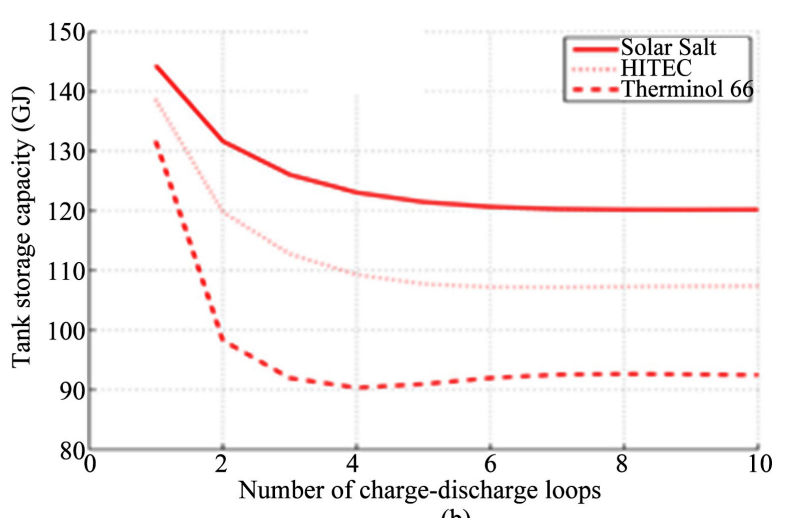

(b)

Figure 7. Temperature profile for different HTFs (a), tank storage capacity for different HTFs (b) [57].

conductivity is not suitable. This shows whether the presence of an optimal value of thermal conductivity for better heat transfers between solid and HTF and internal heat diffusion [27]. In addition the storage utilization factor and the exergy efficiency may be better for liquid HTFs (molten salt and oil) than air due to their higher thermo-physical properties [62]. The Table 2 presents the thermo-physical properties of several fluids for thermal energy storage and heat transfer within a DMT storage tank.

A part from thermo-physical properties a good sensible HTF should have:

Low melting point: a low melting point reduce increase the temperature range of the storage system and its stability reducing the waste of energy use for melting; good chemical stability: high chemical stability of storage materials increases life of energy storage plant. So the HTF should be compatible with the others elements of the storage system. The indices value and water content should be very low to ovoid corrosion of the solid particles, the tank and piping system; low toxicity: the HTFs should not be harmful to health of operators and environment. The mineral oil and synthetic oils derive from petroleum are toxic to the environment, that why HTF like vegetal oils have gained considerable interest [63]; high flammability temperature: the HTFs should be non-flammable and non-explosive. A high flash point and fire point are required when the HTF is oil; low vapour pressure: the HTF should have a low vapor in operational temperature range. High vapor pressure requires pressure withstanding containment at high temperatures. It also requires costly insulation.

\subsection{Impact of Tank Parameters on Thermal Performance}

The tank is the main element of the storage system where there are filer materials. The tank can impact the storage performance through its size (ratio H/D and height), porosity, insulation, position and shape. So these parameters need to be chosen carefully to ensure and optimal operation and to satisfy the required energy. The determination of the tank size is dictated by several operational constraints like the total energy required, the period of the discharge process, the high and low temperature of the HTF, the porosity of the tank and thermo-physical properties of the filler materials and the HTF [60]. 
Table 2. Comparison of thermo-physical properties of some HTFs.

\begin{tabular}{|c|c|c|c|c|c|c|}
\hline TFS/properties & $\begin{array}{c}\rho \\
\mathrm{kg} \cdot \mathrm{m}^{-3}\end{array}$ & $\begin{array}{c}c_{p} \\
\mathrm{~J} \cdot \mathrm{kg}^{-1} \cdot \mathrm{K}^{-1}\end{array}$ & $\begin{array}{c}\rho c_{p} \\
\mathrm{~kJ} \cdot \mathrm{m}^{-1} \cdot \mathrm{K}^{-1}\end{array}$ & $\begin{array}{c}\mu \\
(\mathrm{Pa} \mathrm{s})\end{array}$ & $\begin{array}{c}\lambda \\
\mathrm{W} \cdot \mathrm{m}^{-1} \cdot \mathrm{K}^{-1}\end{array}$ & $\begin{array}{c}T_{\min }-T_{\max } \\
\left({ }^{\circ} \mathrm{C}\right)\end{array}$ \\
\hline \multicolumn{7}{|l|}{ 1. Molten salt } \\
\hline Solar salt [30] & 1899 & 1495 & l & 0.00326 & 0.57 & $221 / 600$ \\
\hline $\mathrm{MgCl} 2-\mathrm{KCl}[27]$ & 1660 & 1150 & 1909 & 0.005 & 0.5 & $426 />500$ \\
\hline Na2CO3-K2 CO3-Li2CO3 [27] & 1848 & 1612 & 2979 & 5.9 & 0.00047 & $398 />500$ \\
\hline $\mathrm{ZnCl} 2-\mathrm{NaCl}-\mathrm{KCl}[27]$ & 1977 & 900 & 1779.3 & 0.0042 & 0.29 & $204 />500$ \\
\hline HITEC [30] [40] & 1640 & 1560 & l & 0.00316 & 0.38 & $142 / 538$ \\
\hline \multicolumn{7}{|l|}{ 2. Vegetal oil (NC) $\left(210^{\circ} \mathrm{C}\right)$} \\
\hline Rapeseed oil [3] & 787.7 & 2492 & 1963 & 0.003155 & 0.143 & $-21 / 250$ \\
\hline Jatropha curcas oil [3] [63] & 778.2 & $2400-2509$ & 1953 & 0.001781 & 0.139 & $3 />200$ \\
\hline \multicolumn{7}{|l|}{ 3. synthetic oil } \\
\hline Therminol $^{\mathbb{R}}$ 66oil $[64]$ & $885\left(200^{\circ} \mathrm{C}\right)$ & $2195\left(200^{\circ} \mathrm{C}\right)$ & I & I & $0.113\left(200^{\circ} \mathrm{C}\right)$ & $/ 400$ \\
\hline Therminol $^{\mathbb{R}}$ VP-1 [65] & 757.7 & 2464.5 & & 0.000185 & 0.0865 & $12 / 400$ \\
\hline sylthermXLT $\left(210^{\circ} \mathrm{C}\right)[16]$ & 660 & 2171 & 1433 & 0.00023 & 0.23 & $-11 / 260$ \\
\hline Coloria [17] [66] & 867 & 2200 & & & & \\
\hline Xceltherm 600 [16] & 736 & 2643 & 1945 & 0.00055 & 0.13 & $-29 / 316$ \\
\hline \multicolumn{7}{|l|}{ 4. Liquide Metals $\left(700^{\circ} \mathrm{C}\right)$ [27] } \\
\hline Sodium & 798 & 1256 & 1002.3 & 0.00018 & 57.5 & \\
\hline Lead-bismuth Eutectic & 9807 & 138 & 1353.4 & 0.0011 & 16.8 & $125 />600$ \\
\hline $\operatorname{Tin}(S n)$ & 6650 & 282 & 1875.3 & 0.0011 & 32 & $232 />6000$ \\
\hline Pure lead $(\mathrm{Pb})$ & 10196 & 141 & 1437.6 & 0.0014 & 19.9 & $327 />600$ \\
\hline \multicolumn{7}{|l|}{ 5. Gasses } \\
\hline $\operatorname{Air}\left(450^{\circ} \mathrm{C}\right)[64]$ & $0.448 / 0.50$ & $1080 / 1190$ & l & l & 0.053 & 0 -infinite \\
\hline
\end{tabular}

The tank volume is ideal when the solid filler material is not taken into account, and can be calculated as follow:

$$
V_{\text {ideal }}=\frac{Q_{\text {total }}}{\rho_{p} c_{p, f}\left(T_{h}-T_{c}\right)}
$$

When taking into account the solid filler material, the real volume of the tank should be calculated by:

$$
V_{\text {real }}=\frac{\rho_{p} c_{p, f}}{\varepsilon \rho_{p} c_{p, f}+(1-\varepsilon) \rho_{s} c_{p s}}
$$


The performance of thermal storage system depending on the effective discharge efficiency, provides the amount of useful energy that the tank can deliver during the discharging process.

\subsubsection{The Effect of the Ratio H/D and the Height on the Thermocline Effectiveness}

The thermal energy storage efficiency increases with the ratio H/D, because high ratio result in higher velocities of the HTFs and consequently a better heat transfer with the solid particles [27] [60] [65]. However when the ratio is higher than around 2.4, the ratio effect becomes negligible [29]. Also the discharge and collection efficiency increase with the height of the vessel [67]. However when the tank is taller than $30 \mathrm{~m}$ there is no more improvement and heat loss become more significant [4]. Figure 8 shows how the ratio H/D and height of the tank can affect the thermocline storage efficiency.

\subsubsection{Effect of Tank Porosity on Thermal Performance}

A low porosity between 0.15 and 0.35 is desirable without compensating much on the effectiveness of the storage system [30].

\subsubsection{The Effective Geometry and Position of Thermocline Storage Tank} Most of the storage tanks studied in the literature are cylindrical [25] [28] [40] [45] [68]. We have also rectangular shape [10] [12] and truncated cone shape [39] [69]. In 2019 based on 2D physical and mathematical model of a novel truncated cone Mao et all have proposed a shell-and-tube TES tank based on enthalpy method. Compare to cylindrical tank the storage efficiency of the truncated cone tank is better and can reach $93 \%$ for heat latent storage system [70]. However, concerning the DMT storage, Ortega et al. 2017, have showed that, the cylindrical tank has a better thermal performance than truncated cone tank fixing the particle size at $1 \mathrm{~cm}$ at the mass flow $0.3 \mathrm{~kg} / \mathrm{s}$ [53], but in term of mechanical performance the conical geometry is better with worse thermal performance.

In the literature we did not yet see any study concerning the DMT thermocline tank position on the thermal performance. However a CFD simulation to analyze thermal stratification in domestic hot water storage $\operatorname{tank(SMT)}$ have given a better results(stratification and discharge efficiency) for the vertical tank than the horizontal one [68] as presented in Figure 9.

\subsubsection{The Influence of Tank Wall Configuration on Thermal Storage Performance}

Based on adiabatic numerical model after tested the influence of heat losses on 1D-2P model, Hoffman et all carried out heat losses through the tank wall for small tanks, but these heat losses may be negligible for large tanks like solar One storage tank [28]. Sometimes the filler materials undergo some amount of volume change due to thermal expansion and mechanical interactions increasing also the tank wall. This expansion of tank wall is from hoop stress due to solid filler material expansion, and may conduct to catastrophic thermal ratcheting and thermocline degradation at high values of hoop stress [9]. 

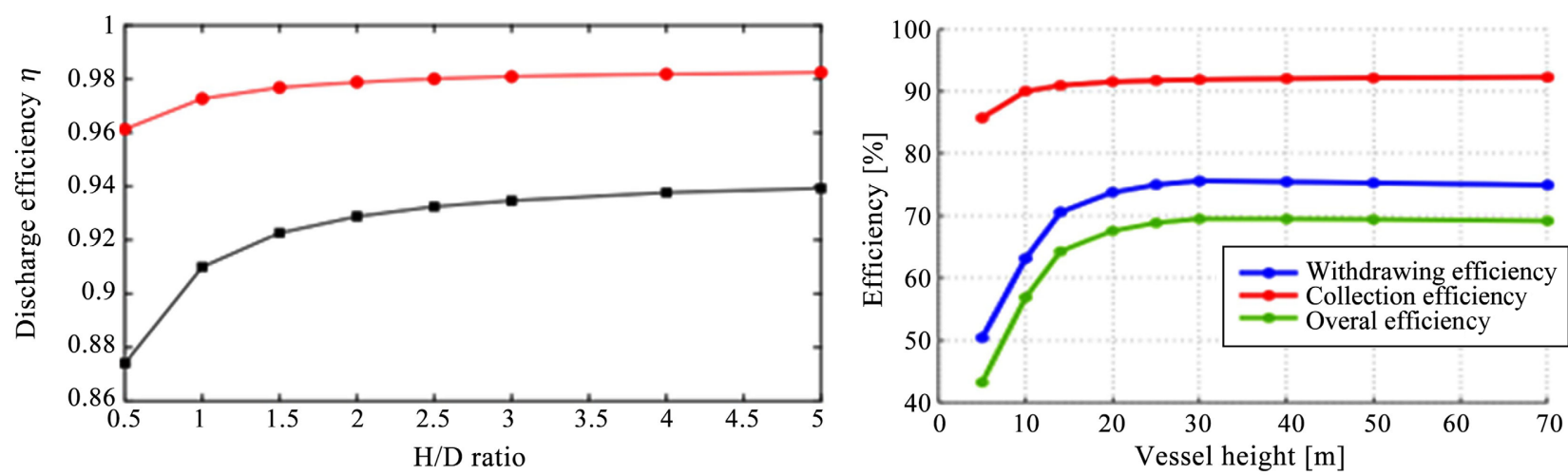

Figure 8. Effect of the ration H/D on discharge efficiency [27] (left) and the variation of discharge, collection and overall efficiency with the tank height [4] (right).

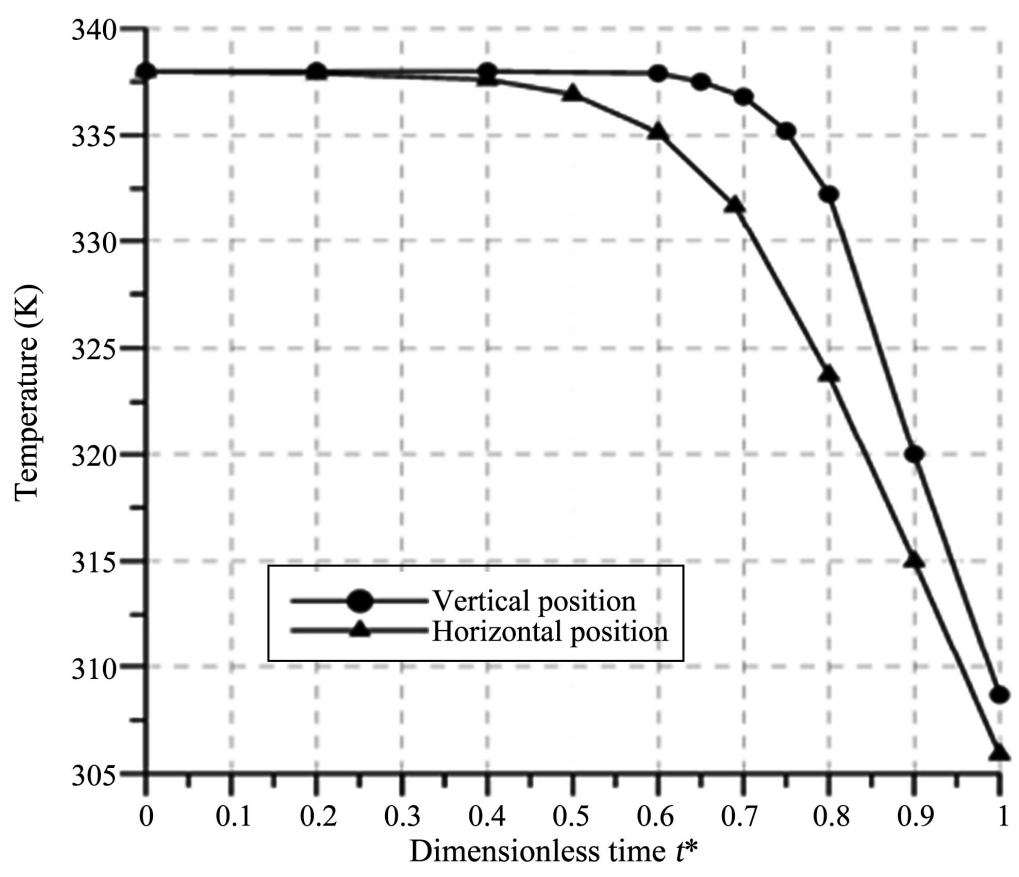

Figure 9. Effect of tank position on thermal energy storage performance.

\section{Conclusion}

In the short to medium term, packed-bed energy storage is a promising technology to enhance the development of solar thermal energy. Thus several studies have been carried out on thermal storage performance based on modelling giving a good accuracy with experimental data from lab and pilot scale system. This review gave us an overview of the different parameters influencing the thermal storage performance, which are the diameter of the filler materials and their properties, the velocity of the HTF and its properties, the ratio H/D, the height, the geometry and position of the tank, porosity and the inlet geometry in the tank. So for a better sizing of the thermocline storage system, all these parameters should be optimum. A better thermal performance can be achieved when adding an encapsulated phase change materials (PCM) [71] [72]. 


\section{Acknowledgements}

This work is part of West African Science Services on Climate Change and Adapted Land Use (WASCAL) ongoing program in Energy at Abdou Moumouni University of Niamey in the faculty of Science \& Technology. This research is also supported by the Laboratory of Physics and Chemistry of Environment through a collaboration between Abdou Moumouni University and Joseph KI-ZERBO university in Burkina Faso. The authors want also to think the Intergovernmental Panel on Climate Change (IPCC) for its interest in this work.

\section{Conflicts of Interest}

The authors declare no conflicts of interest regarding the publication of this paper.

\section{References}

[1] Ummadisingu, A. and Soni, M.S. (2011) Concentrating Solar Power-Technology, Potential and Policy in India. Renewable \& Sustainable Energy Reviews, 15, 5169-5175. https://doi.org/10.1016/j.rser.2011.07.040

[2] Herrmann, U., Kelly, B. and Price, H. (2004) Two-Tank Molten Salt Storage for Parabolic Trough Solar Power Plants. Energy, 29, 883-893.

https://doi.org/10.1016/S0360-5442(03)00193-2

[3] Hoffmann, J. (2015) Stockage thermique pour centrale solaire thermodynamique à concentration mettant en oeuvre des matériaux naturels ou recyclés. Université de Perpignan, Perpignan.

[4] Angelini, G., Lucchini, A. and Manzolini, G. (2014) Comparison of Thermocline Molten Salt Storage Performances to Commercial Two-Tank Configuration. Energy Procedia, 49, 694-704. https://doi.org/10.1016/j.egypro.2014.03.075

[5] SENER (2018) The 150 MW Noor Ouarzazate III Solar Tower Power Plant with Storage System Accomplished the First Synchronization.

[6] Huang, Q., Lu, G., Wang, J. and Yu, J. (2011) Thermal Decomposition Mechanisms of $\mathrm{MgCl}_{2} \cdot 6 \mathrm{H}_{2} \mathrm{O}$ and $\mathrm{MgCl}_{2} \cdot \mathrm{H}_{2} \mathrm{O}$. Journal of Analytical and Applied Pyrolysis, 91, 159-164. https://doi.org/10.1016/j.jaap.2011.02.005

[7] Raade, J.W. and Padowitz, D. (2011) Development of Molten Salt Heat Transfer Fluid with Low Melting Point and High Thermal Stability. Journal of Solar Energy Engineering, Transactions of the ASME, 133, Article ID: 031013. https://doi.org/10.1115/1.4004243

[8] Pacheco, J.E., Showalter, S.K. and Kolb, W.J. (2002) Development of a Molten-Salt Thermocline Thermal Storage System for Parabolic Trough Plants. Journal of Solar Energy Engineering, 124, 153-159. https://doi.org/10.1115/1.1464123

[9] Flueckiger, S.M., Yang, Z. and Garimella, S.V. (2012) Thermomechanical Simulation of the Solar One Thermocline Storage Tank. Journal of Solar Energy Engineering, Transactions of the ASME, 134, Article ID: 041014. https://doi.org/10.1115/1.4007665

[10] Schlipf, D., Faust, E., Schneider, G. and Maier, H. (2017) First Operational Results of a High Temperature Energy Storage with Packed Bed and Integration Potential in CSP Plants. AIP Conference Proceedings, 1850, Article ID: 080024. https://doi.org/10.1063/1.4984445 
[11] Zanganeh, G., et al. (2014) A 3 MWth Parabolic trough CSP Plant Operating with Air at up to $650{ }^{\circ} \mathrm{C}$. 2014 International Renewable and Sustainable Energy Conference (IRSEC), Ouarzazate, 17-19 October 2014, 108-113. https://doi.org/10.1109/IRSEC.2014.7059884

[12] Zunft, S., Hänel, M., Krüger, M., Dreißigacker, V., Göhring, F. and Wahl, E. (2011) Jülich Solar Power Tower-Experimental Evaluation of the Storage Subsystem and Performance Calculation. Journal of Solar Energy Engineering, Transactions of the ASME, 133, Article ID: 031019. https://doi.org/10.1115/1.4004358

[13] Mira-Hernández, C., Flueckiger, S.M. and Garimella, S.V. (2014) Numerical Simulation of Single- and Dual-Media Thermocline Tanks for Energy Storage in Concentrating Solar Power Plants. Energy Procedia, 49, 916-926.

https://doi.org/10.1016/j.egypro.2014.03.099

[14] Py, X. and Olives, R. (2010) Thermal Energy Storage for CSP Processes. In: Yan, J.Y., Ed., Handbook of Clean Energy Systems, Wiley, Hoboken, 1-16. https://doi.org/10.1002/9781118991978.hces189

[15] Stutz, B., et al. (time) Storage of Thermal Solar Energy [Stockage Thermique de L'énergie Solaire]. Comptes Rendus Physique, 18, 401-414.

https://doi.org/10.1016/j.crhy.2017.09.008

[16] Kenda, E.S., N’Tsoukpoe, K.E., Ouédraogo, I.W.K., Coulibaly, Y., Py, X. and Ouédraogo, F.M.A.W. (2017) Jatropha Curcas Crude Oil as Heat Transfer Fluid or Thermal Energy Storage Material for Concentrating Solar Power Plants. Energy for Sustainable Development, 40, 59-67. https://doi.org/10.1016/j.esd.2017.07.003

[17] Radosevich, L.G. (1988) Final Report on the Power Production Phase of the $10 \mathrm{MW} / \mathrm{sub}$ e/ Solar Thermal Central Receiver Pilot Plant. Sandia National Laboratories. https://doi.org/10.2172/7120228

[18] Radosevich, L.G. (1982) Final Report on the Power Production Phase of the $10 \mathrm{MWe}$ Solar Thermal Central Receiver Pilot Plant. https://www.osti.gov/

[19] Dincer, I. (2002) On Thermal Energy Storage Systems and Applications in Buildings. Energy and Buildings, 34, 377-388.

https://doi.org/10.1016/S0378-7788(01)00126-8

[20] Kurs, B. and Okten, K. (2018) Effect of Rectangular Hot Water Tank Position and Aspect Ratio on Thermal Stratification Enhancement. Renewable Energy, 116, 639-646. https://doi.org/10.1016/j.renene.2017.10.013

[21] Battaglia, M. and Haller, M. (2018) Stratification in Large Thermal Storage Tanks. EuroSun 2018 Conference Proceedings, Rapperswil, 10-13 September 2018, 10 p. https://doi.org/10.18086/eurosun2018.13.03

[22] Odenthal, C., Steinmann, W.D. and Zunft, S. (2019) Analysis of a Horizontal Flow Closed Loop Thermal Energy Storage System in Pilot Scale for High Temperature Applications-Part I: Experimental Investigation of the Plant. Applied Energy, 263, Article ID: 114573. https://doi.org/10.1016/j.apenergy.2020.114573

[23] Faust, E., Schlipf, D., Schneider, G. and Maier, H. (2018) Flow Modeling of a Packed Bed High Temperature Thermal Energy Storage System. AIP Conference Proceedings, 2033, Article ID: 090008.

[24] Hoffmann, J.F., Fasquelle, T., Goetz, V. and Py, X. (2016) A Thermocline Thermal Energy Storage System with Filler Materials for Concentrated Solar Power Plants: Experimental Data and Numerical Model Sensitivity to Different Experimental Tank Scales. Applied Thermal Engineering, 100, 753-761.

https://doi.org/10.1016/j.applthermaleng.2016.01.110 
[25] Fernandez, O. (2017) High Temperature Packed Bed Thermal Energy Storage Systems Based on Low Cost Materials. PhD Thesis, Universidad Del País Vasco Euskal Herriko Unibertsitatea, 330 p.

[26] Xu, C., Li, X., Wang, Z., He, Y. and Bai, F. (2013) Effects of Solid Particle Properties on the Thermal Performance of a Packed-Bed Molten-Salt Thermocline Thermal Storage System. Applied Thermal Engineering, 57, 69-80. https://doi.org/10.1016/j.applthermaleng.2013.03.052

[27] Laube, T., Marocco, L., Niedermeier, K., Pacio, J. and Wetzel, T. (2020) Thermodynamic Analysis of High-Temperature Energy Storage Concepts Based on Liquid Metal Technology. Energy Technology, 8, Article ID: 1900908. https://doi.org/10.1002/ente.201900908

[28] Hoffmann, J.F. (2015) Stockage thermique pour centrale solaire thermodynamique à concentration mettant en oeuvre des matériaux céramiques naturels ou recyclés. http://www.theses.fr/2015PERP0033

[29] Graells, A. (2014) Analysis of Heat Storage with a Thermocline.

[30] Reddy, K.S., Jawahar, V., Sivakumar, S. and Mallick, T.K. (2017) Performance Investigation of Single-Tank Thermocline Storage Systems for CSP Plants. Solar Energy, 144, 740-749. https://doi.org/10.1016/j.solener.2017.02.012

[31] Schumann, T.E.W. (1929) Heat Transfer: A Liquid Flowing through a Porous Prism. Journal of the Franklin Institute, 208, 405-416. https://doi.org/10.1016/S0016-0032(29)91186-8

[32] Esence, T. (2017) Étude Et Modélisation Des Systèmes De Stockage Thermique De Type Régénératif Solide/Fluide. Université Grenoble Alpes, Saint-Martin-d'Hères, $242 \mathrm{p}$.

[33] Klein, P., Roos, T.H. and Sheer, T.J. (2014) Experimental Investigation into a Packed Bed Thermal Storage Solution for Solar Gas Turbine Systems. Energy Procedia, 49, 840-849. https://doi.org/10.1016/j.egypro.2014.03.091

[34] Bruch, A., Fourmigue, J.F., Couturier, R. and Molina, S. (2014) Experimental and Numerical Investigation of Stability of Packed Bed Thermal Energy Storage for CSP Power Plant. Energy Procedia, 49, 743-751. https://doi.org/10.1016/j.egypro.2014.03.080

[35] Mahfoudi, N., Moummi, A. and El Ganaoui, M. (2014) Sand as a Heat Storage Media for a Solar Application: Simulation Results. Applied Mechanics and Materials, 621, 214-220. https://doi.org/10.4028/www.scientific.net/AMM.621.214

[36] Esence, T., Bruch, A., Fourmigué, J.F. and Stutz, B. (2019) A Versatile One-Dimensional Numerical Model for Packed-Bed Heat Storage Systems. Renewable Energy, 133, 190-204. https://doi.org/10.1016/j.renene.2018.10.012

[37] Mawire, A., Lentswe, K., Lugolole, R., Okello, D. and Nyeinga, K. (2018) Thermal Stratification Performance of a Packed Bed Latent Heat Storage System during Charging. 2018 6th International Renewable and Sustainable Energy Conference (IRSEC), Rabat, 5-8 December 2018, 1-6. https://doi.org/10.1109/IRSEC.2018.8702960

[38] Zavattoni, S.A., Barbato, M.C., Pedretti, A. and Zanganeh, G. (2015) Evaluation of Thermal Stratification of an Air-Based Thermocline TES with Low-Cost Filler Material. Energy Procedia, 73, 289-296. https://doi.org/10.1016/j.egypro.2015.07.691

[39] Ortega-fernández, I., Zavattoni, S.A., Rodríguez-Aseguinolaza, J., Aguanno, B.D. and Barbato, M.C. (2017) Analysis of an Integrated Packed Bed Thermal Energy Storage System for Heat Recovery in Compressed Air Energy Storage Technology. 
205, 280-293. https://doi.org/10.1016/j.apenergy.2017.07.039

[40] Chang, Z.S., Li, X., Xu, C., Chang, C. and Wang, Z.F. (2015) The Design and Numerical Study of a 2MWh Molten Salt Thermocline Tank. Energy Procedia, 69, 779-789. https://doi.org/10.1016/j.egypro.2015.03.094

[41] Zanganeh, G., Pedretti, A., Haselbacher, A. and Steinfeld, A. (2015) Design of Packed Bed Thermal Energy Storage Systems for High-Temperature Industrial Process Heat. Applied Energy, 137, 812-822. https://doi.org/10.1016/j.apenergy.2014.07.110

[42] Tiskatine, R., et al. (2016) Experimental Evaluation of Thermo-Mechanical Performances of Candidate Rocks for Use in High Temperature Thermal Storage. Applied Energy, 171, 243-255. https://doi.org/10.1016/j.apenergy.2016.03.061

[43] Keilany, M.A., et al. (2018) Vitrified Asbestos Waste Used as Filler Material in a Thermocline Storage Tank. WasteEng 18: 7 th International Conference on Engineering for Waste and Biomass Valorisation, 2-5 July 2018, Prague, 244-253.

[44] Valmiki, M.M., Karaki, W., Li, P., Van Lew, J., Chan, C. and Stephens, J. (2012) Experimental Investigation of Thermal Storage Processes in a Thermocline Tank. Journal of Solar Energy Engineering, Transactions of the ASME, 134, Article ID: 041003. https://doi.org/10.1115/1.4006962

[45] Esence, T., Bruch, A., Fourmigué, J.F. and Stutz, B. (2018) Extended Modeling of Packed-Bed Sensible Heat Storage Systems. AIP Conference Proceedings, 2033, Article ID: 090007. https://doi.org/10.1063/1.5067101

[46] Iniesta, A.C., Diago, M., Delclos, T., Falcoz, Q., Shamim, T. and Calvet, N. (2015) Gravity-fed Combined Solar Receiver/Storage System Using Sand Particles as Heat Collector, Heat Transfer and Thermal Energy Storage Media. Energy Procedia, 69, 802-811. https://doi.org/10.1016/j.egypro.2015.03.089

[47] Diago, M., Iniesta, A.C., Delclos, T., Soum-Glaude, A., Shamim, T. and Calvet, N. (2016) Characterization of Desert Sand as a Sensible Thermal Energy Storage Medium. AIP Conference Proceedings, 1734, Article ID: 050011. https://doi.org/10.1063/1.4949109

[48] Kenda, E.S., Py, X., N’Tsoukpoe, K.E., Coulibaly, Y and Sadiki, N. (2018) Thermal Energy Storage Materials Made of Natural and Recycled Resources for CSP in West Africa. Waste and Biomass Valorization, 9, 1687-1701. https://doi.org/10.1007/s12649-017-9904-2

[49] Py, X., et al. (2011) Recycled Material for Sensible Heat Based Thermal Energy Storage to Be Used in Concentrated Solar Thermal Power Plants. Journal of Solar Energy Engineering, Transactions of the ASME, 133, Article ID: 031008. https://doi.org/10.1115/1.4004267

[50] Alva, G., Liu, L., Huang, X. and Fang, G. (2017) Thermal Energy Storage Materials and Systems for Solar Energy Applications. Renewable \& Sustainable Energy Reviews, 68, 693-706. https://doi.org/10.1016/j.rser.2016.10.021

[51] Khare, S., Dell'Amico, M., Knight, C. and McGarry, S. (2013) Selection of Materials for High Temperature Sensible Energy Storage. Solar Energy Materials \& Solar Cells, 115, 114-122. https://doi.org/10.1016/j.solmat.2013.03.009

[52] Díaz-Heras, M., Belmonte, J.F. and Almendros-Ibáñez, J.A. (2019) Effective Thermal Conductivities in Packed Beds: Review of Correlations and Its Influence on System Performance. Applied Thermal Engineering, 171, Article ID: 115048. https://doi.org/10.1016/j.applthermaleng.2020.115048

[53] Ortega-Fernández, I., Loroño, I., Faik, A. and Uriz, I. (2017) Parametric Analysis of a Packed Bed Thermal Energy Storage System Parametric Analysis of a Packed Bed Thermal Energy Storage System. AIP Conference Proceedings, 1850, Article ID: 
080021. https://doi.org/10.1063/1.4984442

[54] Xu, C., Wang, Z., He, Y., Li, X. and Bai, F. (2012) Parametric Study and Standby Behavior of a Packed-Bed Molten Salt Thermocline Thermal Storage System. Renewable Energy, 48, 1-9. https://doi.org/10.1016/j.renene.2012.04.017

[55] Karim, A., Burnett, A. and Fawzia, S. (2018) Investigation of Stratified Thermal Storage Tank Performance for Heating and Cooling Applications. Energies, 11, Article ID: 1049. https://doi.org/10.3390/en11051049

[56] Hoffmann, J.F., Fasquelle, T., Goetz, V. and Py, X. (2017) Experimental and Numerical Investigation of a Thermocline Thermal Energy Storage Tank. Applied Thermal Engineering, 114, 896-904. https://doi.org/10.1016/j.applthermaleng.2016.12.053

[57] Modi, A. and Pérez-Segarra, C.D. (2014) Thermocline Thermal Storage Systems for Concentrated Solar Power Plants: One-Dimensional Numerical Model and Comparative Analysis. Solar Energy, 100, 84-93.

[58] Elfeky, K.E., Li, X., Ahmed, N., Lu, L. and Wang, Q. (2019) Optimization of Thermal Performance in Thermocline Tank Thermal Energy Storage System with the Multilayered PCM(s) for CSP Tower Plants. Applied Energy, 243, 175-190. https://doi.org/10.1016/j.apenergy.2019.03.182

[59] Esence, T., Bruch, A., Molina, S., Stutz, B. and Fourmigué, J.F. (2017) A Review on Experience Feedback and Numerical Modeling of Packed-Bed Thermal Energy Storage Systems. Solar Energy, 153, 628-654. https://doi.org/10.1016/j.solener.2017.03.032

[60] Bouguila, A. and Said, R. (2020) Performance Investigation of a 100-kWhth Thermocline Packed Bed Thermal Energy Storage System: Comparison between Synthetic Oil and Vegetable Oil. Advances in Mechanical Engineering, 12, 1-10. https://doi.org/10.1177/1687814020905746

[61] Cascetta, M., Cau, G., Puddu, P. and Serra, F. (2014) Numerical Investigation of a Packed Bed Thermal Energy Storage System with Different Heat Transfer Fluids. Energy Procedia, 45, 598-607. https://doi.org/10.1016/j.egypro.2014.01.064

[62] Geissbühler, L., Mathur, A., Mularczyk, A. and Haselbacher, A. (2019) An Assessment of Thermocline-Control Methods for Packed-Bed Thermal-Energy Storage in CSP Plants, Part 1: Method Descriptions. Solar Energy, 178, 341-350. https://doi.org/10.1016/j.solener.2018.12.015

[63] Gomna, A., N’Tsoukpoe, K.E., Le Pierrès, N. and Coulibaly, Y. (2020) Thermal Stability of a Vegetable Oil-Based Thermal Fluid at High Temperature. African Journal of Science, Technology, Innovation \& Development, 12, 317-326. https://doi.org/10.1080/20421338.2020.1732080

[64] Thibaut Esence (2017). Étude et modélisation des systèmes de stockage thermique de type régénératif solide/fluide. https://tel.archives-ouvertes.fr/tel-01714439

[65] Van Lew, J.T., Li, P., Chan, C.L., Karaki, W. and Stephens, J. (2011) Analysis of Heat Storage and Delivery of a Thermocline Tank Having Solid Filler Material. Journal of Solar Energy Engineering, Transactions of the ASME, 133, Article ID: 021003.

[66] Sharma, A., Tyagi, V.V., Chen, C.R. and Buddhi, D. (2009) Review on Thermal Energy Storage with Phase Change Materials and Applications. Renewable \& Sustainable Energy Reviews, 13, 318-345. https://doi.org/10.1016/j.rser.2007.10.005

[67] Yang, Z. and Garimella, S.V. (2010) Thermal Analysis of Solar Thermal Energy Storage in a Molten-Salt Thermocline. Solar Energy, 84, 974-985. https://doi.org/10.1016/j.solener.2010.03.007

[68] Abdelhak, O., Mhiri, H. and Bournot, P. (2015) CFD Analysis of Thermal Stratifica- 
tion in Domestic Hot Water Storage Tank during Dynamic Mode. Building Simulation, 8, 421-429. https://doi.org/10.1007/s12273-015-0216-9

[69] Zanganeh, G., Pedretti, A., Zavattoni, S., Barbato, M. and Steinfeld, A. (2012) Packed-Bed Thermal Storage for Concentrated Solar Power-Pilot-Scale Demonstration and Industrial-Scale Design. Solar Energy, 86, 3084-3098.

https://doi.org/10.1016/j.solener.2012.07.019

[70] Mao, Q., Liu, N. and Peng, L. (2019) Numerical Investigations on Charging/Discharging Performance of a Novel Truncated Cone Thermal Energy Storage Tank on a Concentrated Solar Power System. Advanced Solar Technologies in Buildings, 2019, Article ID: 1609234 https://doi.org/10.1155/2019/1609234

[71] Ahmed, N., Elfeky, K.E., Lu, L. and Wang, Q.W. (2019) Thermal and Economic Evaluation of Thermocline Combined Sensible-Latent Heat Thermal Energy Storage System for Medium Temperature Applications. Energy Conversion and Management, 189, 14-23. https://doi.org/10.1016/j.enconman.2019.03.040

[72] Galione, P.A., Pérez-Segarra, C.D., Rodríguez, I., Oliva, A. and Rigola, J. (2015) Multi-Layered Solid-PCM Thermocline Thermal Storage Concept for CSP Plants. Numerical Analysis and Perspectives. Applied Energy, 142, 337-351.

https://doi.org/10.1016/j.apenergy.2014.12.084 